\title{
What is professional integrity?
}

\author{
Andreas Eriksen \\ Centre for the Study of Professions, Oslo and Akershus University College of \\ Applied Sciences, andreas.eriksen@hioa.no
}

DOI: http://dx.doi.org/10.5324/eip.v9i2.1836

(cc) BY
4his is an open access article distributed under the terms of the Creative Commons Attribution
medium, provided the original author and source are credited.

What is professional integrity and what makes it so important? Policies are designed to promote it and decisions are justified in its name. This paper identifies two competing conceptions of professional integrity and argues that, on their own, both are deficient. In response, this paper develops a third, interpretive view, in which professional integrity is conceived as the virtue of being good on the word of the practice. Professions ask for the public's trust and in doing so, generate a set of legitimate expectations. Judgments of professional integrity are informed by an interpretation of practice that is sensitive to this normative situation.

Keywords: professional integrity, virtue theory, assurance, role interpretation, reasonable disagreement

\section{Introduction}

Integrity is widely regarded as a key virtue for professionals. Two main kinds of reasons are commonly offered to explain the value assigned to professional integrity. The first kind concerns fidelity to the fundamental goals of the role. For example, the appeal to professional integrity in cases of conscientious objection in the medical context is often described in terms of loyalty to profession-specific ends, such as life and health. The second kind of reason is assurance; when issues of corruption and conflict of interest are debated, professional integrity is often emphasized as the virtue that gives us reason to trust role holders to place professional standards above self-interest.

In this paper, I will develop an account of professional integrity as a distinct virtue (rather than just "ordinary" integrity in a special context), involving responsiveness to both fidelity and assurance. This view will be developed in a loosely Aristotelian way, as a response to two alternatives that turn out to be professional vices, which can be traced in the literature on professional integrity. One of these views emphasizes fidelity to the ends of a professional practice, as in health or education; this may be called the teleological view. The other alternative sees professional integrity as a matter of assurance and conceptually identical to ordinary integrity; this may be called the generic view. As a third alternative, I develop the interpretive view. On this account, professional integrity is distinct from 
ordinary integrity but not because of a direct commitment to profession-specific ends. What makes professional integrity distinct is the way in which it calls for an interpretive judgment of what the role requires.

\section{The Teleological View}

The teleological view describes professional integrity as a commitment to key ends of professional practice, as in education or health. Dean Cocking and Justin Oakley (2001) provide a clear example of this approach: "For, characterising the goal of a profession in terms of the substantive good it undertakes to serve helps us better understand appeals to a notion of professional integrity as a reason for refusing to carry out certain requests for patients or clients" (Cocking \& Oakley 2001: 83). Their main example is active voluntary euthanasia, which they claim "is to betray the goal of serving health which fundamentally defines their profession of medicine" (2001: 83). Even if it would be best for the patient to grant his or her autonomous request to be killed, doctors do not feel they act on this request in their capacity as doctors. In this way, the authors differentiate between personal and professional integrity. Active voluntary euthanasia may be compatible with personal integrity, but it must be performed with the "doctor's hat off" (Cocking \& Oakley 2001: 83). Cocking and Oakley refer with approval to an article by Franklin G. Miller and Howard Brody (1995) that expresses similar ideas but with an even stronger emphasis on the conception of professional integrity as concerned with professioninternal values: "The acts of physicians of integrity must serve the proper ends or goals of medicine, and they must be ethically appropriate means to these ends in light of the values and norms internal to the practice of medicine" (Miller \& Brody 1995: 11).

The insistence that professional integrity cannot be reduced to bureaucratic rulefollowing or mere responsiveness to client or patient requests is an attractive feature of this approach. The teleological view accepts rules and requests only insofar as they are sanctioned by a legitimating end. Oliver Wendell Holmes Sr., a physician renowned for his literary skills as well as for reforming medical practices of the day, elegantly elaborated on the importance of this point, expressing only disdain for "plain practical workmen" who "go about the work of the day before them, doing it according to the rules of their craft, and asking no questions of the past or of the future, or of the aim and end to which their special labor is contributing" (Holmes 1860: 8). Holmes drew a striking analogy to one of Sir William Edward Parry's Arctic expeditions. The expedition was supposed to be racing towards the North Pole, but the ice they travelled on was drifting towards the Equator, and this reverse travel would remain undiscovered if everyone kept their eyes strictly on the track they were plodding. Holmes used this story to illustrate the necessity of seeing practice in light of its larger purpose: "It is not only going backward that the plain practical workman is liable to, if he will not look up and look around; he may go forward to ends he little dreams of" (Holmes 1860: 8). Holmes's dreaded "plain practical workman" appears to be the opposite of an agent with professional integrity. The Arctic parable expresses the common understanding that professional integrity is a virtue that demands that role holders lift their gaze and allow their judgments to be informed by a sense of purpose. The virtuous alternative to the 
plain practical workman is a role holder who makes responsible judgments with a reach that extends beyond the immediate task.

The teleological view would deny professional integrity to role holders who are unwilling to make evaluative judgments that reach beyond the immediate task. A doctor of integrity will see his actions in light of the overarching end of promoting health and not simply as performing assorted tasks without further connection. However, Holmes asked role holders to "look up and look around," and the teleological view fails on the "look around" part. The teleological view requires role holders to be faithful to profession-specific ends, but does not ask them to integrate these ends with the wider array of legitimate expectations. ${ }^{1}$ Miller and Brody are very explicit about this: "Ethical considerations of respect for patient autonomy, social utility, and justice lie outside the domain of professional integrity, which constitutes the internal morality of medicine" (Miller \& Brody 1995: 7; see also Lantos, Matlock, \& Wendler 2011: 495).

A figure inspired by the main character of the TV show House M.D. serves to illustrate how this view is problematic. Let's call him Greg, and ignore the interpretive issues and various complexities in the series. Greg has exceptional diagnostic skills and a strong drive to solve medical puzzles. Understanding the nature of an illness is what matters to him, and he does not respect features of practice that constrain the pursuit of this end. According to Greg, procedural requirements, organizational hierarchy, collegial norms, and codes of ethics are more like annoying hurdles than genuine sources of reasons to moderate behavior.

Importantly, Greg's transgressions do not seem to be betrayals of a practiceinternal good. That is, his failings as a professional are not due to a pursuit of goals foreign to the heart of medicine. Greg is not acting in the name of self-interest, nor is he pursuing money or fame. His disrespect for what he considers mere conventions of practice is a consequence of his sincere commitment to providing correct treatment according to his own judgment. Greg only violates norms regulating patient autonomy or confidentiality when he believes there is some medical gain.

Can defenders of the teleological view denounce Greg without altering their conception of professional integrity? That would seem to require a special claim about how the virtue can be possessed. Defenders of the teleological view could bite the bullet and grant Greg professional integrity despite his lack of other virtues. On this reading, Greg is a raw manifestation of professional integrity, purged of all kinds of external side-constraints and independent of other professional virtues. Certainly, this strategy identifies a distinct character trait, but it remains an open question as to whether this trait is a virtue. Do we value such behavior in the role holders we depend on? Advocates of this view might admit that we would not want professionals to be so anarchic and dismissive of shared norms but counter that integrity is only one of many virtues. At least Greg possesses this one virtue, although it would be preferable if he also had others, such as respectfulness and collegiality.

However, this pick-and-mix approach to virtues is untenable. As McDowell (1998) puts it, "the particular virtues are not a batch of independent sensitivities" (McDowell 1998: 53). His example of kindness illustrates how full possession of a virtue requires responsiveness to the requirements of other virtues, such as fairness. What elevates a disposition into a virtue is that it is conducive to right action. But 
the relevant behavior associated with kindness will not always produce right action by itself. Suppose, for instance, that one can express kindness by being sensitive to Mary's feelings and granting her request for something. What then if this request is granted at the expense of a (still valid) promise one has made to Martin? McDowell's point is that the relevant range of behavior associated with one virtue does not lead to right action unless constrained by a sensitivity to other considerations-like, as here, promissory rights. In short, there is unity to virtue; true kindness is not blind to justice. ${ }^{2}$ Similarly, dismissing institutional procedures and widely accepted norms as misguided conventions is not professional integrity but the vice of arrogance. The unity of virtue requires us to reject the claim that "respect for patient autonomy, social utility, and justice lie outside the domain of professional integrity" (Brody \& Miller 1995: 7). Insofar as such broad features of medical ethics are genuine values, professional integrity is not indifferent to them; rather, it is integrated with them.

Is the notion of practice-specific goods simply a red herring in addressing the question of professional integrity? This seems exaggerated, as the teleological view surely captures part of what constitutes the virtue. It is especially disastrous for the integrity of a professional to judge and act irresponsibly with regard to goods that the practice has asked to be trusted with. Acting with integrity in the name of a practice that has promised to promote health requires special rectitude in such matters, and any betrayal of this value poses a specific threat to professional integrity. Furthermore, it seems reasonable to claim that a physician may think as a private individual that active voluntary euthanasia is morally permissible while still seeing it as a break with the requirements of professional integrity. However, the teleological view does not capture the nature of the judgments that lead to such verdicts.

\section{The Generic View}

Let us now consider the opposite view-that professional integrity is not a special value commitment that transcends patient or client expectations but a virtue that gives us reason to trust professionals in the same way that ordinary integrity is a trait that gives us reason to rely on the words of friends and confidants. This view can be found in many accounts of professional integrity; ${ }^{3}$ for present purposes, it will be useful to discuss a recent version of this view, developed by Greg Scherkoske in Integrity and the Virtues of Reason (2013). This account is especially rewarding because it emphasizes aspects of integrity that are of particular importance in the professional context.

Scherkoske argues that integrity belongs to the family of epistemic virtues, along with traits like intelligence, thoroughness, and open-mindedness. On his account, a commitment to the enterprise of excellent judging constitutes integrity (Scherkoske 2013: 88). Persons of integrity are willing and competent to hold and act upon their considered judgments. Unlike people who constantly question their own decisions or backslide in the face of social pressure, persons of integrity take their judgments seriously and are resolute in the face of temptation to waiver. They trust their own convictions when appropriate and suspend their decisions only in light of relevant reasons. 
Central to this account is the idea of connecting integrity to responsibility in offering reasons to others. Agents of integrity have an adequate understanding of their epistemic position and of what kinds of judgment this position entitles them to. They use this understanding to constitute themselves as authors of dependable assurances: "People of integrity are constitutively good on their word: that is, they are good sources of competent and reliable reasons for action and belief" (Scherkoske 2013: 150, italics in original). In other words, persons of integrity are careful when they assert, promise, or use other perfomatives aimed at providing deliberative assurance to the receiver. They take the associated commitments seriously, taking care not to vouch for claims that they are not in a position to validate. In other words, they invite others to rely on their judgment only when it is responsible to do so.

Scherkoske's conception offers more than a phenomenological account of common perceptions of integrity; it also vindicates the idea that this is a genuine virtue-a character trait of value. His account builds on the plausible methodological assumption that both descriptive and normative adequacy are required in defending any conception of integrity (Scherkoske 2013: 16-20). According to Scherkoske, giving an account of integrity is not just about structuring common understandings; it is also about explaining why we are right to value integrity. What makes integrity a virtue in its own right is its importance in contexts where we depend on others: "Integrity is distinctive partly because of why we want it in the persons whom we surround ourselves with, specifically those mentors, friends and advisors upon whose judgment we rely" (Scherkoske 2013: 150, italics in original).

Professionals are perhaps the paradigm case of persons whose word is offered as trustworthy. It is constitutive of professional roles that they aim at being good sources of reasons for belief and action. As the sociologist Everett Hughes formulates the "essence of the professional idea," professionals "profess to know better" (Hughes 1984: 375). Physicians purport to know what is good for our health and offer their judgment as something to be relied upon. Teachers invite us to trust that they know how to educate our children. Lawyers take on our cases with the promise that their legal aid is dependable. In short, professions are institutions that present themselves as worthy of being entrusted with a key social responsibility.

In this vein, Andrew Abbott's influential sociological account describes professions as actively requesting the public to treat their word as singularly trustworthy: "In claiming jurisdiction, a profession asks society to recognize its cognitive structure through exclusive rights" (Abbott 1988: 59). The actual transactions may take many forms, of course. As Abbott explains, "In America it is ultimately through public opinion that professions establish the power that enables them to achieve legal protection. By contrast, on the Continent the state itself has traditionally been the professions' public" (Abbott 1988: 60). The relevant point here is that being good on one's word as a professional involves a responsiveness to public expectations engendered by the claim for a socially recognized jurisdiction.

On this reading, professional practice is constituted by its assurance relation to the public. This frames the virtue of professional integrity within a different conception of practice than that suggested by the teleological view. In particular, it is a deontic conception, emphasizing practice as a source of demands, as opposed to an axiological conception that focuses on the internal values of the profession. The 
general concept of professional practice seems to allow for both readings. Nevertheless, the deontic conception is more appropriate for understanding the value of professional integrity. Seeing professional practice as constituted by an assurance given to the public enables us to connect the virtue to our legitimate expectations. As Scherkoske argued, our reasons for seeking integrity in others is an important aspect of what makes it a distinct virtue. Given that the public entrusts professions with key social responsibilities, it is therefore reasonable to connect the virtue to the assurance relation that has been created.

So far, there has been little reason to doubt the generic view, to which Scherkoske's account is explicitly committed. He claims that distinctions commonly made between types of integrity serve only to "make clear the content of the relevant set of convictions, in the adherence to which a person expresses her integrity" (Scherkoske 2013: 101). That would imply that there are no interesting or substantive differences at the conceptual level, and this claim is not without plausibility, as Scherkoske has made a strong case that integrity is a matter of responsible assurance. Moreover, it has been argued that the notion of assurance is partly definitional of the professions. In other words, professionals are bound by the mechanisms of responsibility that Scherkoske has referred to in explaining integrity.

However, this view should also be considered in relation to Greg. Again, Greg only cares about getting the diagnosis right; routines, codes and norms are to be conformed to only insofar as they are instrumental in solving the case at hand. Although Greg fails to live up to the standard image of a doctor, he exhibits much of what we associate with ordinary integrity. ${ }^{4} \mathrm{He}$ sticks to his best judgment and ignores what he thinks are misguided conventions. He has the courage to put conviction over desire for approval, and he has the strength to hold and act upon his considered judgments. Certainly, he may deceive his patients and colleagues in order to find the key to a particular medical mystery. However, he is generally candid about his overall approach, and he is not afraid to state his actual reasons for action. He is an integrated agent in the sense that his mind is made up on matters of importance, and he speaks his mind when questioned. But is this sufficient to meet the standard of professional integrity?

Defenders of the generic view hold that the ordinary virtue of integrity is sufficient to secure an appropriate responsiveness to role-dependent expectations. However, if that were so, we should ascribe professional integrity to anyone who maintains personal integrity in the work context. The case of Greg illustrates how this creates an internal conflict in the generic view, because it runs counter to Scherkoske's own requirement of normative adequacy. As he claims above, integrity is distinct largely because of why we want it in people we rely on. His conception of ordinary integrity seems plausible partly because it vindicates our sense that it valuable. But this normative condition of conceptual distinctness actually points towards a divide between ordinary and professional integrity. We value professional integrity in role holders largely because it prevents them from acting like Greg. As patients or clients, we encounter professionals as representatives of practices with standards that are supposed to warrant our trust. Whatever one may think of Greg as an illustration of ordinary integrity, he is not good on his word as a professional. He does not take his practice seriously as a shared enterprise with common principles but sees his role as guided solely by his personal judgment. 
Evidently, Greg's opinions on the authority of various norms of professional ethics are likely to diverge significantly from the views of the people who depend on him. This means that the generic view fails according to its own standard; in holding professional integrity to be essentially the same virtue as ordinary integrity, the connection with warranted assurance is lost. That is because the reasons for wanting integrity in persons qua persons differ from the reasons for wanting integrity in role holders qua role holders. When a friend offers advice on how I should deal with a conflict, integrity requires her to state herself as the source of reasons. I value my friend's integrity as excellence in standing for her own beliefs rather than merely paying lip service to what I might approve of (cf. Calhoun 1995). She remains an integrated person by giving her word in a manner that reflects genuine conviction.

Scherkoske would presumably agree that the value of professional integrity does not refer to personal conviction in this straightforward sense. As already mentioned, his own notion of warranted assurance would disqualify Greg from being good on the word of his practice. Nevertheless, the generic view fails to give us an account of what Greg should be doing instead. What we need is an account that describes a mode of practical reasoning that can live up to this standard. As discussed in relation to the entrusted nature of professional practice, the standard of assurance that Scherkoske associates with integrity has definite appeal in the professional context. For the remainder of this paper, I will defend the claim that integrity as responsibility to be good on one's word takes on a distinct form in the professional context. Professional agents hold roles that purport to be trustworthy in light of their public standards, and this implies a break with the view that integrity is generic.

\section{The Interpretive View}

The central claim of the interpretive view is that for professional integrity to connect with assurance it must be an interpretive virtue. I develop this view by following the lead provided by Andrew Edgar and Stephen Pattison (2011). They characterize professional integrity as a mode of reasoning that calls for the role holder to engage critically and creatively with the varied and sometimes conflicting demands of practice. They describe the virtue as both an "interpretive stance" and a "deliberative capacity and competence which is deployed in the context of complex professional and organizational work to find appropriate answers and ways forward" (Edgar \& Pattison 2011: 103). Daniel E. Wueste (2014) emphasizes something similar in his discussion of cheating and the duty to report it within academic institutions; integrity requires recognition that ethical decisions are "situated" in a "cluster of relationships that enriches but also, inevitably, makes things complicated rather than simple" (Wueste 2014: 20).

These approaches indicate a conception of professional integrity in which interpretive and evaluative engagement with practice is central. In developing the interpretive view, I will connect the notions of being "situated" and taking an "interpretive stance" more systematically to professional integrity. First, what is the fundamental normative relation that governs the situation? It is a promissory relation, where the profession has given its word to the public. Role holders are situated as promisors. What is the object of interpretation? It is professional practice 
as a framework for decision-making. The main idea is that for professionals to be good on the word of their practice, they must act on a defensible interpretation of what their practice has promised.

The first step is to give Greg the proper moral diagnosis, and it has been argued here that the two preceding views could not do so. His main failure is not a betrayal of health, the key good of his practice. Nor is it a lack of willingness or competence to stand behind his considered judgments. Rather, he lacks professional integrity because he does not act in the name of his practice. Formal requirements, codes of ethics, institutional hierarchies, and collegial norms are among the features of professional practice that engender public expectations of professional role holders. For example, Greg's medical practice is subject to norms regarding respectful consultation and patient autonomy. Greg does not acknowledge the authority of these standards, which means that the word of the practice does not have the normative force to override his personal judgment.

Evidently, the alternative to Greg cannot simply be Holmes's dreaded "plain practical workman," who simply acts on the most straightforward and literal reading of role requirements. As already mentioned, professional integrity is often associated with a refusal to carry out certain role requirements (e.g. abortion and euthanasia). We do not wish to entrust key social goods such as health, education, and legal justice to role holders who surrender their ethical judgment in executing their role. In developing the interpretive view here, the goal is to provide an alternative to both Greg and the practical workman, both of whom fail to achieve an integrated understanding of the practice they represent. Greg does not integrate his sense of professional purpose with the existing features of practice. The practical workman, on the other hand, does not integrate his interpretation of practice with a sense of purpose. It is time to introduce a third character.

In articulating the interpretive view, it will be helpful to borrow the figure of a "chain novelist" from the theory of adjudication developed by Ronald Dworkin. He compares the task of judges to the task of authors engaged in a "chain novel" (Dworkin 1985: 158-162; 1986: 228-238). This comparison elicits a mode of reasoning that has general relevance in the professions. A chain novel is written one chapter at a time, and each finished chapter is passed along to a new author, who writes the next one. The task of each author is to make this the best novel it can be. It must unfold as a coherent story rather than as a mishmash of different visions. This calls for an integrated view of the story elements. The chain novelist "must take up some view about the novel in progress, some working theory about its characters, plot genre, theme, and point, in order to decide what counts as continuing and not as beginning anew" (Dworkin 1986: 230). According to Dworkin, this analogy is apt both to describe and to justify the actions of judges, who know that they are deciding disputes in the name of a practice that has given principled verdicts in similar cases. The good judge views earlier decisions "as part of a long story he must interpret and then continue, according to his own judgment of how to make the developing story as good as it can be" (Dworkin 1986: 239).

Why suppose that the figure of a chain novelist has relevance for professional integrity? Judges are continuing the "story" of law in a readily comprehensible sense, but their standard for decision-making is not obviously applicable to professional roles in general. In order to see the relevance of the chain novelist, we must consider why the analogy was introduced in the first place. The theory of legal 
adjudication is a response to the fact that judges have to decide "hard cases" that cannot be read straight off the books. How statutes should be applied or precedent invoked is usually open to argument when cases reach court. Judges must rule in favor of a particular reading of the law; the question is what makes one reading better than another. The key end of legal practice is justice, so one might suppose that decisions are better or worse according to the standard of justice. That is, good legal decisions aim for outcomes that conform to a vision of what is morally due to those involved. This sort of answer would suit Greg, if he were a judge. It fits his mode of operation, which is to focus directly on the key end of his profession. However, it would also reintroduce the problems we encountered above. What counts as a just outcome is open to considerable disagreement, and the direct application of justice therefore places too much responsibility on the role holder while failing to explain the authority of the decision.

Dworkin's standard for adjudication involves justice, but not as a direct measure of the quality of legal decisions. As he emphasizes, there is no "license for each judge to find in doctrinal history whatever he thinks should have been there" (Dworkin, 1985: 160). His figure of the chain novelist is opposed to the idea that judges should be guided directly by their perception of moral desert. Rather, their role is to reach an integrated view, where justice is draped "in workclothes," as one commentator has put it (Postema 1997). That is, judgments are informed by a conception of justice contained within the grounds of existing law. This conception is likely to be imperfect by the judge's own lights, just as a chain novelist will be disappointed with certain story developments. Nevertheless, neither role holder is entitled to start with a blank slate or make decisions untainted by compromise.

This barely scratches the surface of Dworkin's complex theory of legal adjudication, but it helps to show how the chain novelist represents a mode of reasoning that distinguishes professional integrity. Unlike being good on one's word as an ordinary agent, the professional agent represents a practice that has engendered a multifarious set of legitimate expectations. Professionals face the interpretive challenge of trying to understand how such provisions as codes, organizational procedures, and norms constitute the word of the profession. Like the chain novelist, they must make their decisions in light of an understanding of what others have done, why they have done it, and what this entitles the public to expect. The next two sections will elaborate this idea by defending it against two objections.

\section{Why Interpret?}

The first objection concerns the need for interpretation. One can accept Dworkin's model of legal adjudication and still deny that it captures anything essential about professional integrity. Is interpretive judgment a distinct and essential aspect of professional integrity? One reason to doubt the relevance of the chain novelist is that the case of judges is idiosyncratic, as they must make decisions that are inherently tied to interpretive disputes. Judges are in court in the first place because of disagreements over legal decisions, which means their integrity is obviously dependent on responsibility in interpretation.

However, the idea here is not that every professional role involves interpretive tasks on a par with adjudication. It is difficult to see, for instance, how the 
interpretations made during surgery are similar in any relevant way to legal interpretation. Instead, the claim is that all professional roles are executed in the name of a practice, and that the word of the practice requires interpretation precisely because the practical import of the assurance relation is open to reasonable disagreement. Nevertheless, even this claim may seem suspect. One could claim that the mission of the classic professional roles is settled and that no fundamental disputes remain - that is, that professional practice does not require an interpretive stance.

To find an illustrative case for this objection, we need look no further than the role of legal representatives. The role of lawyers is supposedly to defend the interests of their clients by means of the various instruments available to them through the legal system. A good lawyer will "without fear defend the interests of his client and without regard to any unpleasant consequences for himself or to any other person" (International Code of Ethics, 1956/1964, 6.6). Lawyers owe loyalty only to their clients, and their mission is to secure every possible advantage obtainable through the legal system. For example, they may use delaying tactics in order to make it too costly for the opponent to proceed, or instigate countersuits merely to create conflicts of interest. In short, they offer their skills to the client without any concern for legal deserts. The adversarial system will in itself realize legal justice; lawyers need not be directly concerned with this end. Why, then, should interpretive judgments matter here?

This objection is misguided in a sense that helps to clarify the point of the interpretive view. Anyone who held this view of the lawyer's role would be offering a deeply evaluative understanding of the notion of zealous representation. In Tim Dare's terminology, they would interpret the lawyer role as committed to "hyperzeal" instead of "mere-zeal" (Dare 2009: 76-86). Hyper-zeal is concerned merely with the interests of clients. This attitude recommends using tricks of the trade to secure every possible advantage obtainable with legal instruments. Mere-zeal, on the other hand, is about achieving the proper legal deserts for clients. The goal is to secure legal entitlements rather than interests as such. Dare delivers a forceful defense of mere-zeal as the proper understanding of zealous representation. In doing this, he is taking a normative stand on what it means to be good on the word of the practice. The point here is not to argue in favor of the notion of mere-zeal but rather to emphasize the disputed nature of the ends of professional practice. As noted by another author, Dare's interpretation "strikes some lawyers as deeply confused" (Wendel 2010: 79).

The ends of medical practice are no less disputed. The previously mentioned claim by Cocking and Oakley that active voluntary euthanasia involves a betrayal of the key good of medicine aimed in part to explain how health as an end distinguishes medical professional integrity. However, in referring to the article by Miller and Brody (1995), they inadvertently reveal how professional integrity is bound up with interpretive judgment of the role. Miller and Brody do not tie medical integrity to the pursuit of health in any straightforward sense. Instead, they state three fundamental goals for the practice of medicine: healing, promoting health, and helping patients to a peaceful and dignified death (Miller \& Brody 1995: 11). These diverging views on the nature of medicine lead to different framings of particular decisions. Those who reject the act of helping patients to a peaceful and dignified death as a fundamental goal of medicine are also likely to reject 
institutional procedures and requirements for euthanasia as legitimate parts of practice. For these role holders, their understanding of medicine does not extend to helping patients to a dignified death. Insofar as they conform to institutional regulations connected to euthanasia, they consider this to be external to their true practice.

Many accounts of professional integrity emphasize the complexity of cases and the conflicting expectations that professionals encounter. The above examples from law and medicine indicate how responsible resolution of such complexity and conflict builds on an interpretation of the word of the practice. The normative force of client and patient requests depends on what role holders understand their role to be. Am I the mouthpiece of my client? Does my practice involve helping patients to a dignified death? Professionals of integrity reason responsibly about such questions. They see themselves as part of a practice that has offered its word to the public, and they recognize their responsibility to achieve clarity about what this means. In this regard, the notion of interpretation as highlighted by the figure of the chain novelist expresses a distinct and important dimension of professional integrity.

\section{Why Respect Flawed Decisions?}

The second objection to the interpretive view concerns the connection between professional integrity and features of practice that are judged by the role holder to be misguided or inadequate. The interpretive view requires role holders to continue the story they are part of, even when it rests on decisions that one disagrees with. For example, professionals of integrity comply with established norms of patient autonomy even when they believe that patients would be better off in a more paternalistic institution. Neither the teleological view nor the generic view offers any reason to think that role holders of integrity should comply with flawed decisions. However, one might counter that this is a strength of these views, and that professional integrity is antithetical to compromise. In rejecting Greg as a model of professional integrity, are we not disconnecting this virtue from the notion of morally responsible judgment?

This objection gains momentum from the plausible constraint that Gabriele Taylor places on integrity's deliberative point of view: “The person of integrity will not repeatedly act against her evaluations" (Taylor 1985: 119). Any account of professional integrity lacks credibility if it denies that actions should be responsive to one's best judgment. How does this reflect on the figure of the chain novelist, who complies with flawed decisions? Unlike Greg, who always acts according to his own vision, the good chain novelist continues the story in ways that cohere with the preceding installments. So, is the interpretive view more interested in coherence than in getting it right?

This objection rests on a misleading distinction between aiming for coherence and acting on one's best judgment. It fails to acknowledge that the relevant coherence is a matter of fidelity to the assurance given to the public. Professionals of integrity are good on the word of their practice, which requires integration of the various features of practice into a coherent response to legitimate expectations. While this may involve integrating flawed decisions, it is not a call for a surrender of judgment or action against one's own evaluations. On the contrary, professionals of 
integrity act according to their best reading of practice. Moreover, their interpretation proceeds on the background condition that the practice is a justifiable social institution. As such, it holds authority for the role holder as a legitimate framework for action in circumstances of reasonable disagreement on how to realize values such as health promotion, legal justice, or education provision. There is no contrast between integrity and moral judgment here because the legitimate role is constituted by a binding social agreement on what counts as legitimate grounds for professional action.

Compare this with Kant's (2009) conception of the use of reason in entrusted offices. He describes the clergyman who disagrees with the doctrines of the church. As he notes, this priest is acting in "someone else's name" and will therefore expound the teachings of the church in the entrusted manner. However, Kant emphasizes that misguided features of his practice are not simply executed without interpretive judgment:

He then extracts as much practical value as possible for his congregation from precepts to which he would not himself subscribe with full conviction, but which he can nevertheless undertake to expound since it is not in fact wholly impossible that they may contain truth (Kant 2009: 5).

This remark is interesting because it identifies two tasks for evaluative judgment. First, the features of practice that form the material for interpretation must be reasonable or legitimate. This coheres with the account of integrity defended above. Professionals of integrity do not integrate illegitimate aspects of practice into their understanding of the role. For example, priests are divided on the issue of gay marriage. Priests who believe that it is sinful to carry out such ceremonies are prevented by their professional integrity to do so. Other priests may hold that the directives rest on a reasonable conception of core religious values, even though they would not themselves recommend the institutionalization of gay marriage. The latter group is not prevented by their professional integrity to carry out the ceremony. In Kant's words, role holders of integrity comply with directives when it is not "wholly impossible that they may contain truth."

The second task of evaluative judgment mentioned by Kant is to "extract as much practical value as possible" from the given materials of the role. This task is constructive, and the interpretive view emphasizes that it must be guided by a sense of professional purpose. The figure of the chain novelist represents a particular mode of extracting value in light of professional purpose. Like chain novelists, professionals of integrity join the narrative of a story that is partially developed but not predetermined. The challenge is to continue the story in a way that realizes its best potential. Ideally, judgments made in the name of professional practice draw on grounds that affirm the assurance relation to the public. These judgments are informed by existing rules and procedures in a way that realizes the word given to the public.

\section{Conclusion}

The interpretive view explains professional integrity as a virtue concerned with both fidelity to practice and assurance to the public, connecting these features by 
emphasizing the role of evaluative judgment. In being good on the word of their practice, professionals of integrity are responsive to the entrusted nature of their responsibility. From various sources of legitimate expectations, they extract the most compelling vision of how to realize the ends of their profession. Like chain novelists who must continue a partly written story, they recognize the normative force of even the flawed features of practice and integrate them into their conception of the role.

However, good chain novelists recognize when the story has gone astray and are obligated to bring it back on track. In this regard, the interpretive view highlights how objections in the name of professional integrity deliver a distinct verdict. Requirements that conflict with professional integrity are not merely wrong or misguided; they represent a break with the word of the practice. The force of such a verdict is obscured when integrity is interpreted as loyalty to an "internal" morality, narrowly concerned with profession-specific ends. That conception reduces professional integrity to a matter of preserving the domestic purity of practice. The true merit of the virtue lies elsewhere. Its importance is explained by the aim of making our trust in role holders warranted. Objections that appeal to professional integrity address the public as promisee. The justificatory weight of such appeals depends on whether the alleged break is supported by a responsible reading of practice.

\section{Acknowledgments}

The article has benefited from comments by Anders Molander, Edmund Henden, and members of the GPPS group at Centre for the Study of Professions. I am also grateful to Morten Magelssen for the opportunity to present an early version at the Centre for Medical Ethics.

\section{Notes}

${ }^{1}$ In this regard, we can distinguish between a wide and narrow reading of the teleological view. On the wide reading, the profession-specific good that professional integrity is concerned with includes considerations of justice, patient autonomy, etc. It is possible to argue that Cocking and Oakley belong in this wide category because of two features of their account: first, their inclusion of "side constraints" that regulate the means to pursue the internal goals of practice; second, their slightly paradoxically formulated idea that health as the proper goal of medicine is more than health (Cocking \& Oakley 2001: 90-92). However, the wide reading leads to further questions concerning how integrity is conceived as a unified virtue when tied to a wider array of considerations. It is, at best, the beginnings of an account of professional integrity.

${ }^{2}$ I am only committed to what Gary Watson (1984) calls the "weak unity thesis," which says that in order to have one virtue you must be sensitive to considerations relevant to the others. McDowell endorses the stronger claim that "no one virtue can be fully possessed except by a possessor of all of them" (McDowell 1998: 53).

${ }^{3}$ Cox, La Caze and Levine (2003: 103) attribute the generic view to Benjamin (1990, chs. 3 and 6), Calhoun (1995), Grant (1997), and Halfon (1989). To some extent, 
this attribution rests on implicit assumptions in the texts. Cox, La Caze and Levine provide a brief critical discussion of the view in general terms, but as Pritchard (2006: 67-68) has argued, their own alternative goes too far in the other direction, as they make professional integrity a distinct virtue for every individual profession.

${ }^{4}$ Greg's disregard for general moral considerations does not disqualify him from being an agent of integrity on Scherkoske's account, in which the connection between integrity and moral conviction is allegedly "frequent but contingent" (Scherkoske 2013: 63). Scherkoske claims that standards of ordinary integrity can be understood in a non-moral sense. On his account, failure to be good on one's word is an "abuse of the illocutionary norms and commitments internal to assurance" (Scherkoske 2013: 179); so, lack of integrity amounts to abuse of perfomatives like promising or assertion, but supposedly, this does not necessarily involve moral standards.

\section{References}

Abbott, A. (1988). The system of professions: An essay on the division of expert labor. Chicago, University of Chicago Press.

Benjamin, M. (1990). Splitting the difference: compromise and integrity in ethics and politics. Lawrence, University Press of Kansas.

Calhoun, C. (1995). Standing for something. The Journal of Philosophy 92(5): 235260. http://dx.doi.org/10.2307/2940917

Cox D, La Caze M, Levine, M.P. (2003). Integrity and the fragile self. Aldershot, Ashgate.

Dare, T. (2009). The counsel of rogues? A defence of the standard conception of the lawyer's role. Burlington, Ashgate Publishing.

Dworkin, R. (1985). A matter of principle. Cambridge, Harvard University Press.

Dworkin, R. (1986). Law's empire. London, Fontana Paperbacks.

Edgar, A., Pattison, S. (2011). Integrity and the moral complexity of professional practice. Nursing Philosophy 12(2): 94-106. http://dx.doi.org/10.1111/j.1466769X.2010.0048 1.X

Grant, R.W. (1997). Hypocrisy and integrity: Machiavelli, Rousseau, and the ethics of politics. University of Chicago Press. http://dx.doi.org/10.7208/chicago/ 9780226305929.001.00 01

Halfon, M.S. (1989). Integrity: A philosophical inquiry. Philadelphia, Temple University Press.

Holmes, O.W. (1860). Currents and counter-currents in medical science: An address delivered before the Massachusetts Medical Society, at the Annual Meeting, May 30, 1860. Ticknor and Fields

Hughes, E.C. (1984). The sociological eye: selected papers. New Brunswick, Transaction Books.

Kant, I. (2009). An answer to the question: "What is Enlightenment"? (H.B. Nisbet, trans). Penguin Books. 
Lantos, J., Matlock, A., Wendler, D. (2011). Clinician integrity and limits to patient autonomy. JAMA, 305(5): 495-499. http://dx.doi.org/10.1001/jama.2011.32

McDowell, J. (1998). Virtue and reason. In J. McDowell, Mind, Value, and Reality. Cambridge, Harvard University Press, pp. 50-73.

Miller, F.G., Brody, H. (1995). Professional integrity and physician-assisted death. Hastings Center Report 25(3): 8-17. http://dx.doi.org/10.2307/3562107

Oakley, J., Cocking, D. (2001). Virtue ethics and professional roles. Cambridge, Cambridge University Press. http://dx.doi.org/10.1017/CBO9780511487118.

Postema, G. (1997). Integrity: Justice in workclothes. Iowa Law Review 82: 821-855

Pritchard, M.S. (2006). Professional integrity: Thinking ethically. Lawrence, University Press of Kansas.

Scherkoske, G. (2013). Integrity and the virtues of reason: Leading a convincing life. Cambridge, Cambridge University Press. http://dx.doi.org/10.1017/ CBO9780511732270

Taylor, G. (1985). Pride, shame, and guilt: Emotions of self-assessment. Oxford, Clarendon Press.

Watson, G. (1984). Virtues in excess. Philosophical Studies 46(1): 57-74. http://dx.doi.org/10.1007/BF00353491

Wendel, W.B. (2010). Lawyers and fidelity to law. Princeton, Princeton University Press. http://dx.doi.org/10.1515/9781400836581.

Wueste, D.E. (2014). Promoting integrity integritively: Avoiding the Scylla and Charybdis of abdication and zealotry. Achieving ethical excellence. Research in Ethical Issues in Organizations 12: 5-27 http://dx.doi.org/10.1108/S1529209620140000012001 
